\title{
Recommendation for a Simple, Office-Friendly, Standardized Testing for Head Lice
}

\author{
Craig G. Burkhart ${ }^{*}, 1$ and Craig N. Burkhart ${ }^{2}$ \\ ${ }^{1}$ University of Toledo College of Medicine, USA \\ ${ }^{2}$ University of North Carolina at Chapel Hill, Chapel Hill, North Carolina, USA
}

\begin{abstract}
Given the number of anecdotal and market-driven reported studies on head lice and also the growing resistance to many present insecticides, standardized, inexpensive testing of topical lice therapies should be formalized. Such tests could then be performed by all individuals interested in epidemiology and treatment outcomes with this disease. A simple in vitro office test that requires no high tech services or expensive equipment is presented which has been already helpful to document effectiveness or recalcitrance to specific therapies. In the protocol, head lice are exposed to insecticides for similar durations and concentrations as the product dictates; thus, exposure imitates routine clinical usage of the specific product tested. The results of such testing mirrors actual treatment results much better than elaborate pediculicidal tests performed at certain laboratories.
\end{abstract}

Head lice infestation is a prevalent and highly communicable medical condition infesting millions of elementary school students annually. Given the number of anecdotal and market-driven reported studies on head lice $[1,2]$, assessment of topical lice therapies should require standardized testing which can be performed by individuals interested in epidemiology and treatment outcomes with this disease. Because of growing resistance to many present insecticides, a simple in vitro office test that requires no high tech services or expensive equipment is helpful to document effectiveness or recalcitrance to a specific therapy. Such testing eliminates product assessment error due to factors inherent with in vivo studies, such as improper usage of product and/or fomite reinfestation.

Insects for testing can be obtained by finger grasping individual head lice while foraging through patients' scalps, but there is an easier way. With dry combing, one rakes a lice comb through sections of the scalp, removing lice captured between the metal teeth of the comb or obtaining the lice that detach from the hair onto clothing during brushing. Alternatively, one can perform wet combing by first moistening the scalp hair with water and a commercially available hair conditioner, prior to combing with a fine-toothed metal head lice comb. By this later method, the comb is periodically skimmed onto a clean white paper, and lice are sought within the conditioner residue.

Captured lice are then immersed into the same dilution and for the same time as clinical protocol dictate for that individual product. Thereafter, the lice are transferred into a container of water simulating the rinsing of medication from the hair, before being placed on a cloth disc. Lice activity would then be monitored continuously both visually and by a

*Address correspondence to this author at the University of Toledo School of Medicine, 5600 Monroe Street, Suite 106B, Sylvania, OH 43560, USA; Tel: 419-885-3403; Fax: 419-885-3401; E-mail: cgbakb@aol.com standard light microscopy (or by a magnifier) for hourly durations. If an insecticide fails to be pediculicidal, the insect will routinely begin physical movement within eight hours after insecticidal exposure. Of note, lice mortality after 24 to 36 hours due to physiologic desiccation is normal. A more detailed description of this method is available [3].

Of note, lice are less dependent than mammals for continuous nervous control of respiration and circulation. The exact point of death is not readily defined. With efficacy testing in head lice, the end point must reflect irreversible morbidity or death. Thus, death cannot be simply defined as lack of motor activity on probing, or irreversible intoxication defined as paralysis or continuous tonic-clonic spasm. Cessation of normal body functions such as physical movements and gut peristalsis need to be documented for several hours to confirm expiration.

Of note, the simple testing recommended above, is reproducible and its results reflect results obtained in unbiased clinical trials. By protocol, the head lice are exposed to insecticides for similar durations, concentrations, and exposure imitating routine clinical usage. It mirrors actual treatment much better than elaborate pediculicidal tests performed at certain laboratories $[4,5]$. The results of testing by this simple, office-friendly, standardized testing are reportable, reproducible, and genuinely reflect expected results from clinical studies $[3,6]$. Such a testing procedure allows any one, any where, and at any time, the ability to properly assess therapeutic value of specific head lice products.

\section{REFERENCES}

[1] Burkhart CG. Relationship of treatment-resistant head lice to the safety and efficacy of pediculocides. Mayo Clin Proc 2004; 79: 661-6.

[2] Roberts RJ, Burgess IF. New head-lice treatments: hope or hype? Lancet 2005; 365: 8-10.

[3] Burkhart CN, Burkhart CG. Recommendation to standardize pediculicidal and ovicidal testing for head lice (Anoplura: Pediculidae). J Med Entomol 2001; 38: 127-9. 
[4] Pollack RJ, Kiszewski A, Armstrong P, et al. Differential permethrin susceptibility of head lice sampled in the United States and Borneo. Arch Pediatr Adolesc Med 1999; 153: 969-73.
[5] Thomas DR, McCarroll L, Roberts R, et al. Surveillance of insecticide resistance in head lice using biochemical and molecular methods. Arch Dis Childhood 2006; 91: 777-8.

[6] Burkhart CG, Burkhart CN. Clinical evidence of lice resistance to over-the-counter products. J Cutan Med Surg 2000; 4: 199-201.

Received: November 3, 2008

(C) Burkhart and Burkhart; Licensee Bentham Open.

This is an open access article licensed under the terms of the Creative Commons Attribution Non-Commercial License (http://creativecommons.org/licenses/by$\mathrm{nc} / 3.0 /$ ) which permits unrestricted, non-commercial use, distribution and reproduction in any medium, provided the work is properly cited. 